\title{
Systematic Mapping Study of Enterprise Resource Planning
}

\author{
Salma Shofia Rosyda, Erna Maulina, Margo Purnomo
}

\begin{abstract}
Enterprise resource planning needs to be maximized in line with technological developments and circumstances that can change unexpectedly. The goal is to integrate business processes to enhance collaboration. Organizational performance and critical success factors have become important in enterprise resource planning from 2011 to 2020. This article aims to classify, identify scientific publications, and thematic analysis of the latest literature to create a broad and detailed understanding of enterprise resource planning. The research method used is a systematic mapping study (SMS) to examine scientific publications produced from time to time, types of research, and methods. The SMS procedure follows established empirical guidelines and the mapping data relies on the IEEE, ScienceDirect, and Scopus electronic databases. Based on the results of SMS, it is known that 89 studies met the inclusion criteria. 89 articles were classified by type of paper, method, focus, locus, and year of publication. Then, categorization and quantification of current studies are generated on various dimensions, topic summaries, and current research trends.
\end{abstract}

Keywords: Enterprise Resource Planning, Systematic Mapping Study, SMS.

\section{INTRODUCTION}

Companies are organizations that process economic resources and expertise that create goods and services to serve consumers and bring benefits to the company [1]. In this era, competition in the business world is growing rapidly, companies that do not have the ability to compete and adapt to changing circumstances that can occur unexpectedly will make it difficult to survive or even be eliminated from the business world [2]. One of the surprising conditions that brought about major changes was the COVID-19 pandemic.

Covid 19 brings technology in companies to be used to the fullest. The technology used by the company should be different from other companies, this is done to increase competitive advantage [3, 4]. During this pandemic, the use of ERP is even more maximized so that the role of managers is important so that the loss of many face-to-face and office networks that have been adapted for employee work does not interfere with work. One technology that is widely used today

Manuscript received on June 13, 2021.

Revised Manuscript received on June 18, 2021.

Manuscript published on June 30, 2021.

* Correspondence Author

Salma Shofia Rosyda*, Student, Master of Business Administration Department, Faculty of Social and Political Sciences, Padjadjaran University, Bandung, Indonesia. Email: salma19004@mail.unpad.ac.id

Erna Maulina, Lecturer, Department of Business Administration, Faculty of Social and Political Sciences, Padjadjaran University, Bandung, Indonesia. Email: erna.maulina@unpad.ac.id

Margo Purnomo, Lecturer, Department of Business Administration, Faculty of Social and Political Sciences, Padjadjaran University, Bandung, Indonesia. Email: purnomo@unpad.ac.id

(C) The Authors. Published by Blue Eyes Intelligence Engineering and Sciences Publication (BEIESP). This is an open access article under the CC BY-NC-ND license (http://creativecommons.org/licenses/by-nc-nd/4.0/) in the company is information systems. The system that is widely used by companies today is enterprise resource planning. This statement is based on a literature study conducted, it is known that from 2011 to 2020 the use of enterprise resource planning (ERP) tends to increase.

The business benefits of an excellent ERP system include integrating business processes, sharing business information, better communication and collaboration, improving supply chain and customer relationship management, faster response to market changes, reducing inventory, shortening cycle times, lowering costs, improving productivity, and better customer service [5]. ERP System application is a complex project that takes time, and the process is faced with great opportunities and enormous risks. To take advantage without being influenced by the existing risks, it is very important to be aware of the critical success factor (CSF). This CSF is very important when planning the adoption and implementation of a system, or an existing system needs to be upgraded or replaced. The following is the CSF for ERP applications [6]:

1. Top management support

2. Business process reengineering

3. User engagement

4. Effective project management

5. Staff education and training

6 . Vendor support

The phenomenon of Enterprise Resource Planning (ERP) that is widely known today is how the performance of organizations that implement ERP to help complete work. In addition, organizational culture did not escape the interest of researchers, because related to the application of ERP there were also changes in organizational culture. Furthermore, the critical success factor of ERP application is also considered considering that ERP application is not a simple and inexpensive thing. To obtain existing research, researchers conducted a systematic mapping study, this study was included in the literature perspective [7].

The purpose of the systematic mapping study in this research is to form a background for further research and gain deeper insight into the study of corporate resource planning. In the search, the researcher uses an electronic database to find articles that discuss corporate resource planning. The SMS study is the right method as a literature study approach because it is supported by 89 articles from searches in the IEEE, ScienceDirect, and the Scopus electronic database. Overall, the researchers analyzed the search results of 89 studies with the main questions (Research Questions) in this study including:

Blue Eyes Intelligence Engineering and Sciences Publication

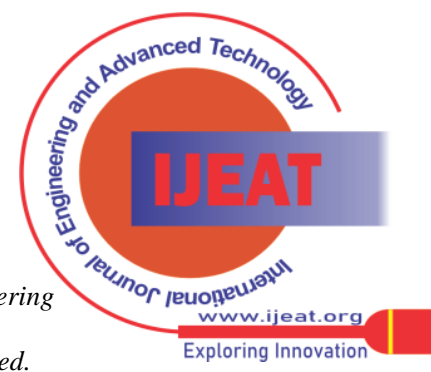


- RQ1: How to focus research on topics that have been researched?

- RQ2: How to locus research on the topic that has been studied?

- RQ3: How is the paper type used?

- RQ4: How methodologies and approaches

- RQ5: How the distribution of paper types and methods used?

- RQ6: How the publication trends each country and every year in this study?

The results of this study provide a comprehensive research approach on corporate resource planning as well as its application and guidelines for practitioners and other practitioners.

\section{LITERATURE REVIEW}

\section{A. History of Enterprise Resource Planning}

The forerunner of ERP appeared in the 1960s under the name Inventory Management and Control in the 1960s with the function of identifying inventory needs, setting targets, providing replenishment techniques, and monitoring the use of goods [8]. The limitations of this system are that it is large, rigid, and requires experts to run it. In the 1970s MRP hardware and software development emerged with the goal of moving towards strategic markets, emphasis on integration and production planning, utilizing software applications to schedule production processes, and the birth of SAP. The limitations of MRP include that the system is difficult to operate, time-consuming, expensive to implement, and does not reflect production and management objectives [9].

The third development was marked by the emergence of MRP II in the 1980s [10]. The purpose of creating this system is for manufacturing resource planning, focusing on manufacturing strategies designed to replace stand-alone systems, sales, inventory, and purchasing transactions, updating inventory and accounting information. The limitations that exist in this system include the absence of a scheduling function, run on one platform, Requires accurate information and information.

The term ERP appeared in the 1990s. The purpose of ERP is to evaluate the extent to which the software is truly integrated both across sections and in various functions that can run on multiple platforms. There are several functional areas offered by ERP including marketing, finance, and HR. The limitations of this system lie in its implementation which may require major changes in the company and its processes, involves a continuous implementation process, may never end, and limited expertise becomes time-consuming. ERP functions are as follows [11]:

1. Support competitive advantage strategy

2. Support decision making

3. Support the company's business processes and activities

\section{B. Enterprise Resource Planning}

The information and communication technology revolution has had a huge impact on the course of human history. Inefficient traditional practices were then abandoned towards electronic-based ways of working, whether in the form of e-commerce, e-budgeting, and even e-management using MIS [12]. One type of MIS is ERP [11]. ERP plays an important role in the management of contemporary business technology. The business benefits of an excellent ERP system include integrating business processes, sharing business information, better communication and collaboration, improving supply chain and customer relationship management, faster response to market changes, reducing inventory, shortening cycle times, lowering costs, improving productivity, and better customer service [5].

ERP is basically a corporate resource planning and management concept that includes parent company data. ERP is usually used by companies in managing and carrying out integrated supervision with work units within the company [11]. ERP is a business software package that combines software into a modular to meet all enterprise requirements which is a knowledge framework to automate and combine all business tasks such as purchasing, inventory control, resources, production planning, and finance [13].

\section{ERP Main Failure Factors}

If the failure factor is not considered, it can cause financial losses, maybe even cause bankruptcy. There are three main factors that can be said to be responsible for the failure of the ERP system from the company side, namely: [13]:

- Inability of employees to use ERP

- Lack of training for employees

- Employee Resistance

- Lack of commitment from the highest level of management

\section{Dimensions of Enterprise Resource Planning}

To provide benefits to users, organizations must have quality IS. Using an empirical test of DeLone and McLean's information system success model, Livari (2005) found that perceived system quality was a significant predictor of user satisfaction with the system, but not system use. In addition, user satisfaction was found to be a strong predictor of individual impact. In DeLone \& McLean, offers an updated model that reflects the critique of others and the situation at the time [14]. Since the service concept is added to IT with the use of the internet, including the quality of service, the description, and drawing of the model are as follows [13-21]:

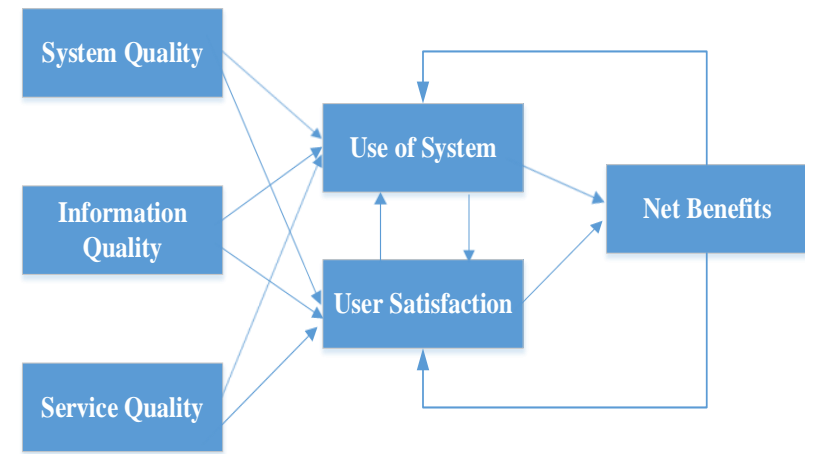

Fig 1: ERP Model

Published By:

Blue Eyes Intelligence Engineering

and Sciences Publication

(C) Copyright: All rights reserved.

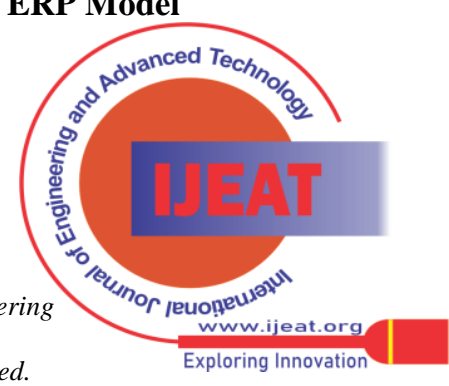




\section{A. Quality System}

System quality is related to bugs, interface consistency, and ease of use taking into account performance and functionality characteristics. The quality of the system includes the quality of processing information systems that contain elements of software and data, as well as a measure of the success of the system. System quality affects the acceptance of information systems and improves organizational performance.

\section{B. Information Quality}

System quality is a desirable characteristic of an Information quality is defined as the extent to which information is produced. Good quality is to present information that is accurate, relevant, complete, and in the form required by users.

\section{Service Quality}

The results of the mapping study show that there is a positive relationship between service quality and performance. The success of the organization depends on how well the information system services. Service quality reliability results in timely and efficient decision making thereby increasing the internal efficiency of the organization.

\section{System Usage}

System use refers to the degree and method by which employees and customers use information system capabilities such as purpose, amount, frequency, nature of use, suitability, and level of use. The relationship between the use of information systems with organizational performance is a positive relationship.

\section{E. User Satisfaction}

User satisfaction is an evaluation of the various individual, organizational, and social consequences of using an information system. The measure of user satisfaction is a measure of the net benefits perceived by information system stakeholders. User satisfaction is the approval or preference of the SI and its output. Factors that mediate user-perceived improvements in service levels or system performance for information system success. For example, user satisfaction levels include reports, systems, and services.

\section{F. Net Benefits}

Net benefits are increased decision making, cycle time reduction, efficiency, effectiveness, system cost, business process improvement, the enabler for desired business processes, increased organizational flexibility, increased innovation capability, revenue impact, and profit impact.

\section{RESEARCH METHOD}

This research is a secondary study with a systematic mapping study (SMS). SMS itself comes from the study literature review (SLR) SMS serves to describe the types of research activities that have been carried out. Systematic mapping studies describe research at a high level and map research rather than investigating it in detail [4]. SMS is a method to get an overview of a particular research area [23]. The parts of the SMS are as follows:

\section{A. Research Question}

Research questions in SMS are much broader than in
SLR to address a wider scope of the study [23]. The main purpose of SMS is to map the frequency of publications over time to find out research trends. The second objective is to identify forums where research has been published. This goal is reflected in the research question (RQ) as shown [24]. The research questions of this study concentrate on categorizing topics in the field of enterprise resource planning.

\section{B. Search Steps}

The general description of SMS is traced from time to time, so that the systematic mapping study obtained is the current state achieved and the current condition based on all scientific evidence in a particular field of research, within a certain period of time [25]. The search uses three electronic databases, namely IEEE, ScienceDirect, and Scopus.

The search keywords were created using the strategy of Banaeianjahromi and Smolander. The last step is to use the Boolean operator whose function is to synthesize into a single search string [26]. The keyword used is "enterprise resource planning" with 23,613 journal findings. The category of exclusion articles or exclusion criteria and inclusion articles which are one of the mapping study activities in order to abort irrelevant articles and sort out relevant articles are determined afterward. The following are the inclusion and exclusion criteria formulated [27]:

Table- I: Inclusion and Exclusion Criteria

\begin{tabular}{|l|}
\hline \multicolumn{1}{|c|}{ Inclusion } \\
\hline - Research focusing on ERP research. \\
- Articles that use English. \\
- Writing published in 2011-2020. \\
\hline \multicolumn{1}{|c|}{ Exclusion that discuss ERP in detail. } \\
\hline - Papers that do not discuss about ERP. \\
- Languages other than English. \\
- The unpublished writing of 2011-2020. \\
\hline
\end{tabular}

After the inclusion and exclusion criteria were established, a systematic mapping study flow was made to describe in detail the picture of the research stages and the results that were issued from each stage of the search.

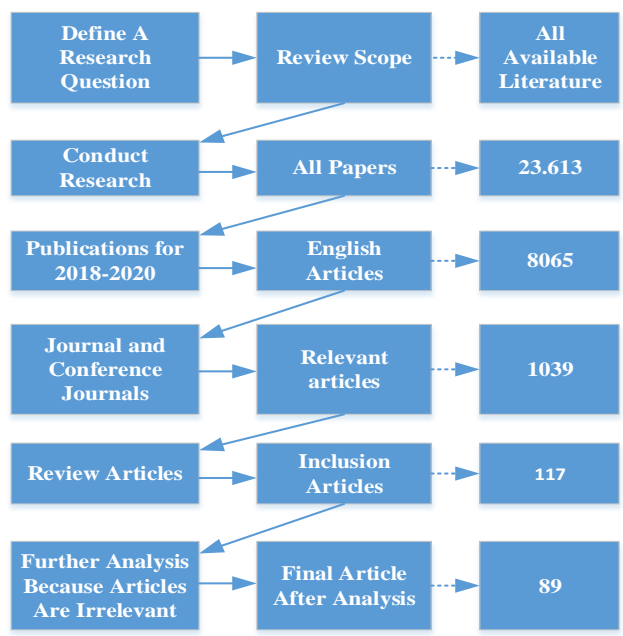

Fig 2: SMS Process

Published By:

Blue Eyes Intelligence Engineering and Sciences Publication

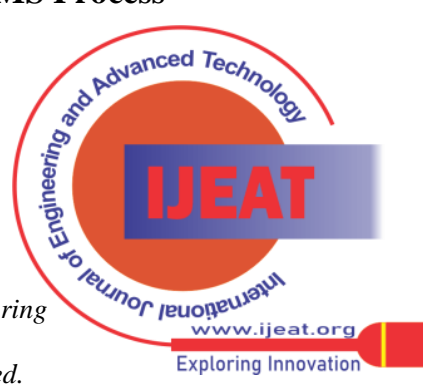




\section{RESEARCH RESULT AND DISCUSSION}

This section is the result of mapping based on research questions. Based on the mapping results from 89 articles on enterprise resource planning, they are grouped using Microsoft Excel applications with the categories of research focus, locus, country, methods, and paper type.

\section{A. Research Focus (RQ1)}

To answer RQ1, 89 articles were classified on research topic areas (research focus) with the categories CSF, Innovation, Leadership, Learning, Organizational Capabilities, Organizational Performance, RBV, Strategy, Supply Chain, TQM.

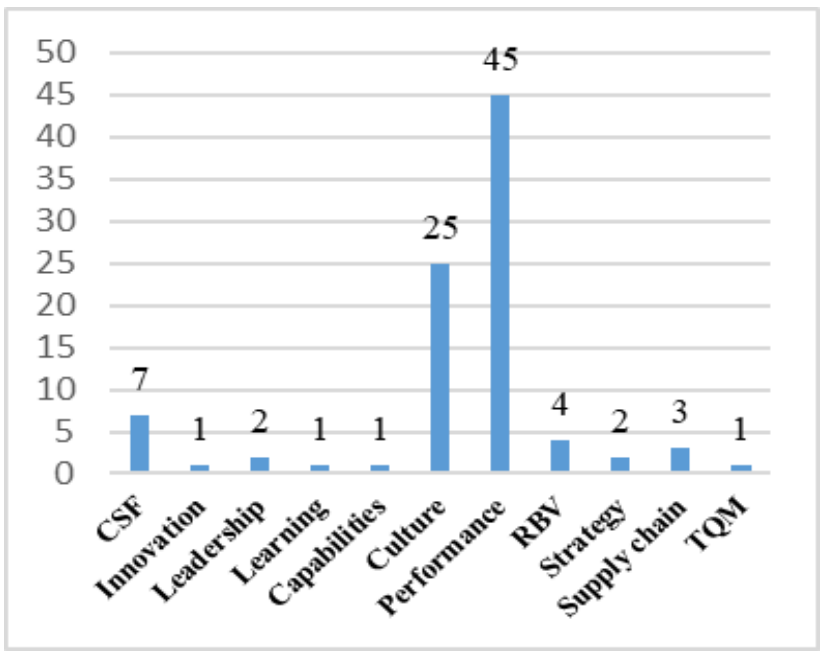

Fig 3: Research Focus

\section{B. Research Locus (RQ2)}

To answer RQ2, 89 articles were classified in the research locus area with the categories: Enterprise, Organization, and Small-medium enterprise.

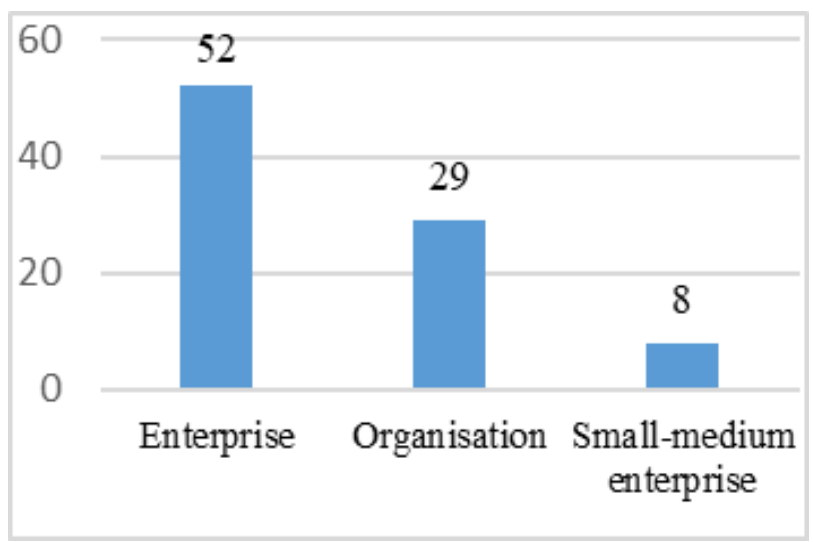

Fig 4: Research Locus

The most studied locus is an enterprise with 52 articles, the organization ranks second with a total of 29 studies, while the last place is occupied by the small-medium enterprise with 8 journals.

\section{Paper Type (RQ3)}

Research is grouped into several types of research such as evaluation research, philosophical papers, solution proposals, validation research. To provide answers from RQ3, we categorized 89 studies based on classification mapping.

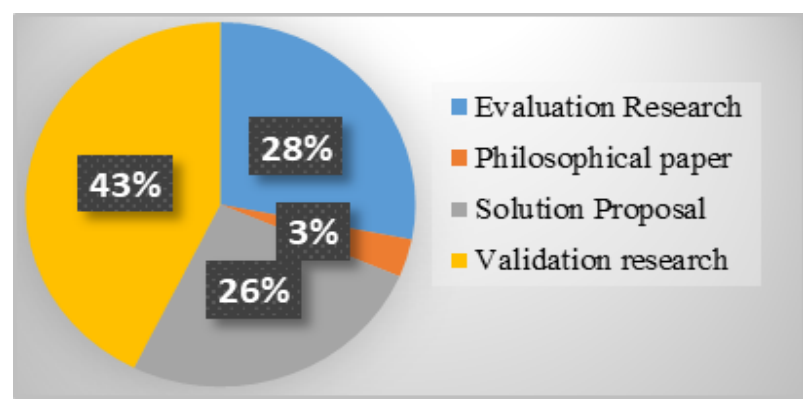

Fig 5: Distribution of Research Type

\section{Research Methods and Approaches (RQ4)}

The research is grouped into six categories of methods, namely case study, constructive study, discussion paper, grounded theory, literature study, and survey. To provide an answer from RQ4 below is a diagram illustrating the percentage distribution of research methods regarding ERP.

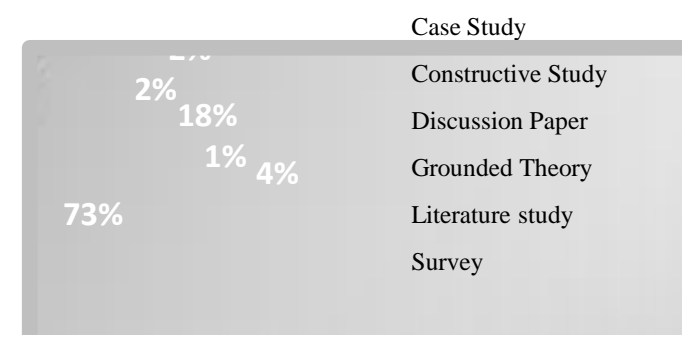

Fig 6: Distribution of Research Method

The results of systematic mapping show that the most frequently used research method is survey with a total of 64 (73\%) studies. The next most frequently used article method is the discussion paper method $16(18 \%)$, followed by literature study 3 (4\%). The second last position is occupied by case studies and constructive studies by $2 \%$ with a total of 2 articles, the last position is occupied by grounded theory by $5 \%$ with a total of 1 article. The following is a diagram illustrating the conditions of the research approach to ERP in 2011-2020 on the IEEE, ScienceDirect, and Scopus electronic databases:

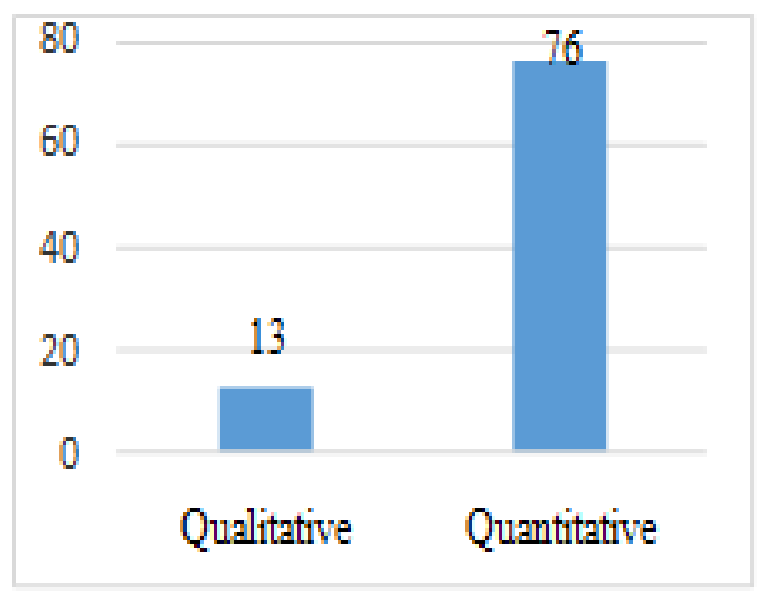

Fig 7: Research Approach

Published By:

Blue Eyes Intelligence Engineering

and Sciences Publication

(C) Copyright: All rights reserved.

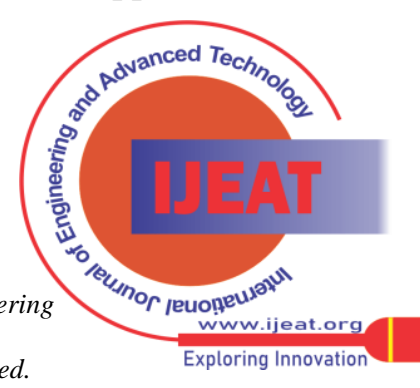




\section{E. Distribution of Research Types and Methods (RQ5)}

After mapping the distribution results, it is known that validation research and surveys with 35 articles occupy the highest position, the second position is occupied by the type of solution proposal research and 17 studies survey methods, the third is occupied by evaluation research with a survey method of 12 articles, the fourth is occupied by the type of evaluation research using the method.

Discussion paper research as many as 8 studies. In the fifth place, there are solution proposals accompanied by discussion paper research methods totaling 6 studies. Evaluation research and solution discussion occupy the next research with 3 studies. Philosophy journals and constructive study research methods rank second to last with a total of 2 studies while the last one is occupied by case study research methods as many as two journals accompanied by different types of research, namely evaluation research and validation research. The following is a bubble diagram that describes the distribution of research types and research methods regarding ERP.

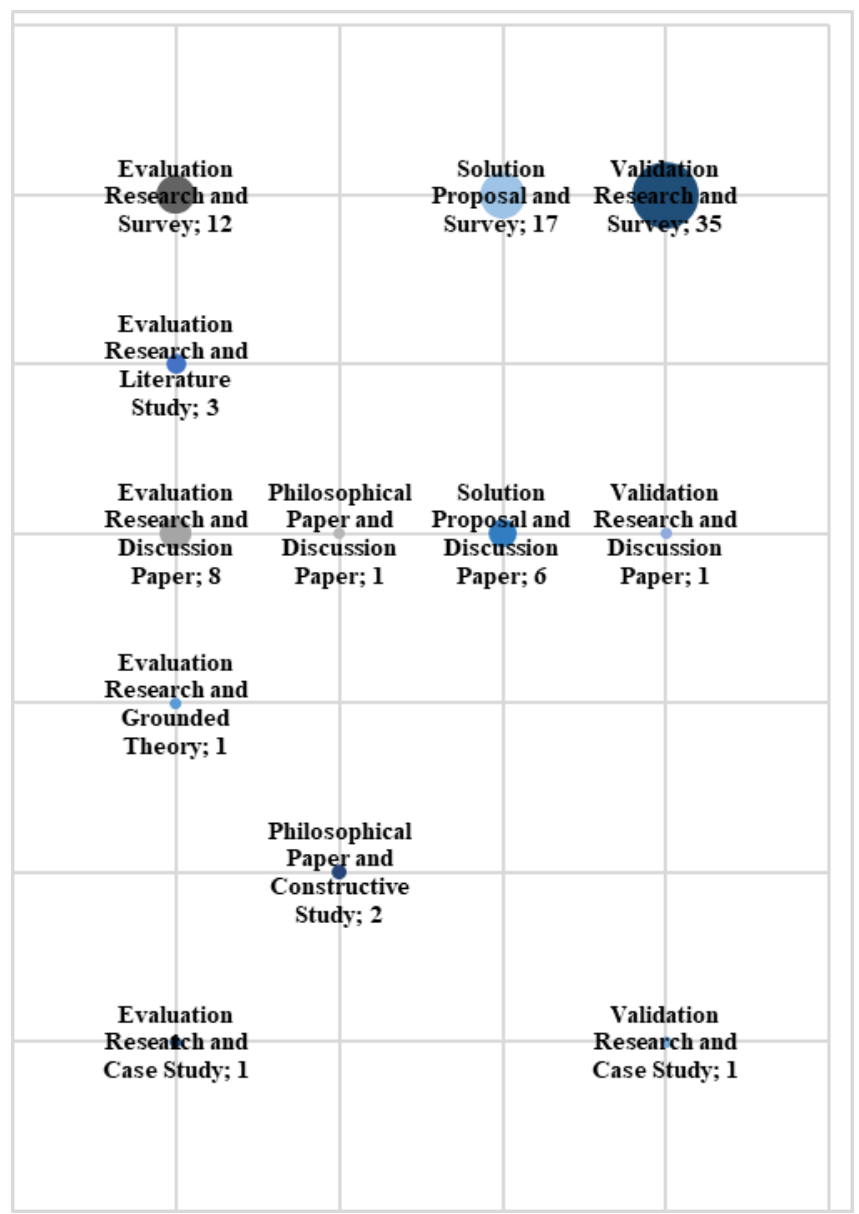

Fig 8: Distribution of Paper Types and Methods

\section{F. Publication Trend (RQ6)}

Based on the mapping results, it was found that the most countries that produced research on enterprise resource planning were America, China, Malaysia, and Taiwan with 9 studies from each of these countries. The second is occupied by the Portuguese with 8 studies. The UK ranks third with 5 studies from 2011 to 2020. Austria, Indonesia, Thailand, and Greece rank fourth with 4 studies published from each of these countries. Jordan and Spain are in fifth place with 3 publications, the second last place is occupied by Saudi

Published By:

Blue Eyes Intelligence Engineering and Sciences Publication

Arabia, the Netherlands, Lebanon, and Tunisia which issued 2 publications each. Finally, each country only publishes 1 research, namely Brazil, Dubai, Finland, Israel, Korea, Poland, France, Romania, Sweden, and Turkey.

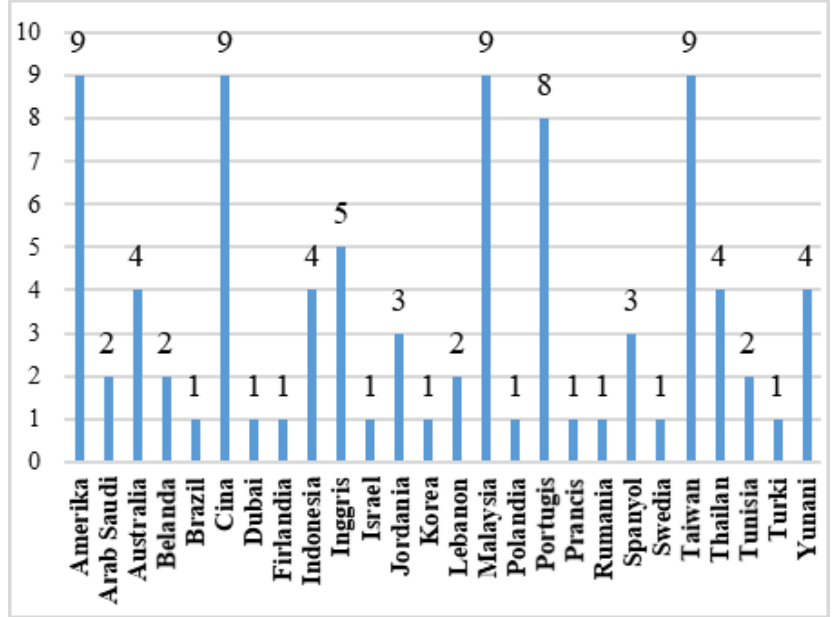

Fig 9: Publication Trends by Country Prepare Your Paper Before Styling

The image below is a research trend published in electronic database media from 2011-2020. In 2013 and 2014 there were 14 articles, the highest among the other 8 years. 2011 and 2015 took second place with 9 articles. The third was occupied in 2014 with 7 studies. Furthermore, in 2018 and 2020 with published research as many as 6 studies. In 2017 from the mapping results, it was found that at least 4 publications had been published.

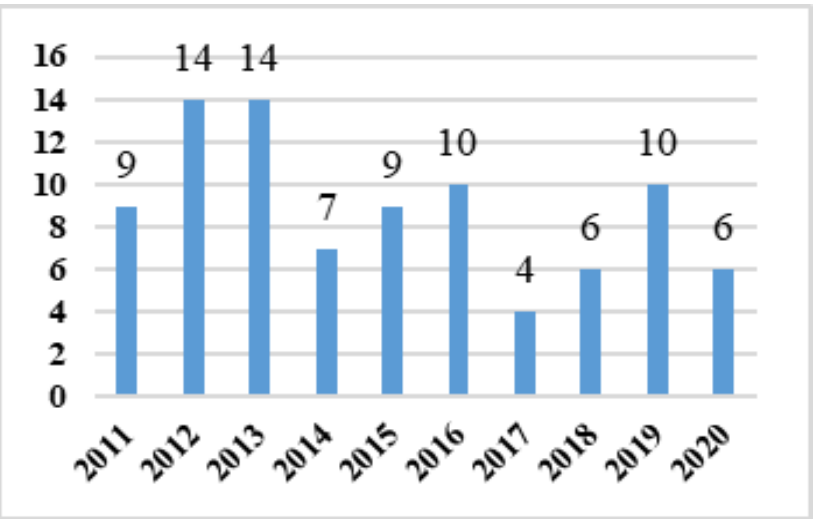

Fig 10: Publication Trends from Year to Year

A systematic mapping study describes the whole of ERP. We found 89 relevant articles and then we developed a classification scheme that categorizes articles based on research focus, research type, and research method. Surveys and discussion papers are the most widely used research for ERP research in companies, organizations, and SMEs.

It is concluded that validation research mostly uses survey methods followed by the use of survey methods with solution proposal research types. The three survey methods are evaluation research.

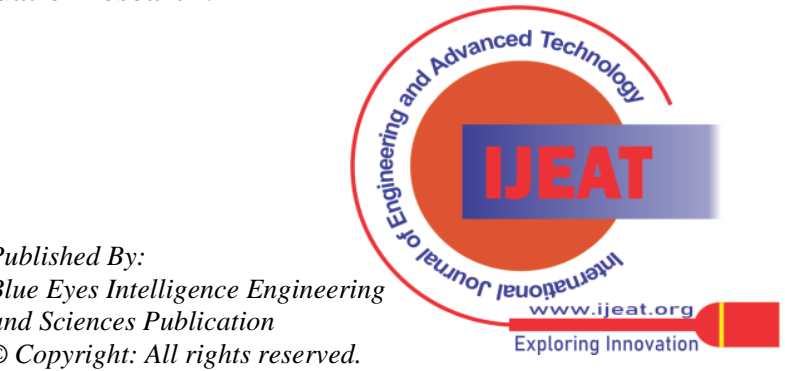


In this systematic mapping process, there are limitations, among which the journal search is only sourced from three electronic databases so that it cannot cover all existing journal and conference databases. In addition, we only take the category of articles in English. Enterprise resource planning encourages workers to upgrade their abilities, especially in using information technology and adapt to its use. This drive is directly proportional to the many benefits of optimal ERP applications such as integrating business processes, sharing business information, better communication and collaboration, improving supply chain and customer relationship management, faster response to market changes, reducing inventory, shortening cycle times, lower costs, increase productivity, and better customer service.

Most ERP applications that do not affect organizational performance or hinder organizational performance are caused by the inability of workers to use ERP to the fullest. But more than that, the majority. When a company decides to apply something big, it will certainly affect the organizational culture, this is due to changes in the way of working, the tools used, the software used to work, etc. These changes must be controlled by managers during socialization and application to ensure that the work does not have too many obstacles or better yet there are no obstacles when switching to more digitization.

In fact, ERP was created as a strategy to make work easier thanks to automation that can be tailored to the needs of each organization, more than the goal, there are important factors for successful ERP application considering that the ERP application process is not short, time-consuming and requires no small amount of money. From these success factors, it is also known what are the main causes of ERP failure to be applied to the organization. These innovations are carried out to achieve competitive advantage so that although many companies have this system, it must have its own uniqueness in each organization. In this pandemic, ERP is also increasingly supporting the work of employees where work is done remotely. Organizations are increasingly adapting their systems to be able to operate flexibly from anywhere.

This description is in line with the many studies on ERP that have been carried out by researchers around the world. It can be concluded from the results of a systematic mapping study that ERP continues to develop, especially in terms of its function, this is to support business conditions and dynamic changes along with the times and changes in external conditions that have an impact on the internal organization. This development can be seen in the history section.

\section{CONCLUSION}

The rapidly changing business environment and increasingly fierce global competition have led to the need for ERP to improve organizational performance in various aspects. This study maps the ERP literature. The main motivation of the mapped study is to provide an overview of the existing literature on ERP as an organizational or enterprise sustainability solution. From systematic mapping, research articles can be classified based on a research method approach with topics that are widely discussed regarding management, strategy, and technology. Then the research is grouped into several types or types of research and mapped the trend of the country of origin of publication from 2011-2020. The results of this study provide a guide to assist researchers in planning future research through finding research gaps (Gaps).

Although a lot of research on ERP has been done, it seems that learning about ERP still has its own problems. One example is the lack of employees both within the company and from outside parties who can operate the company's ERP correctly, quickly, and effectively. The focus is still limited in the number of researches in 2011-2020, namely on communication, ethics, organizational resilience in the face of change, and the economy.

\section{FUTURE RESEARCH SUGGESTIONS}

Literature on CSF, RBV, Supply Chain, Leadership, Strategy, and TQM is still difficult to find although these focuses are also very important to note. Critical success factors are important to note because even though they already exist in CSF theory, the type of organization and organizational circumstances are different from each other. Of the six core CSFs, there may be different trends between companies. RBV related to the resources owned by the organization that can bring the success of an organization is also an important value because ERP is not a resource that can stand alone to achieve its success. The role of other resources such as human resources in the organization is needed so that their utilization can be maximized. ERP system implementation is not a small change so the role of the leader is important in its implementation. Strategy is certainly needed in its implementation, this is because implementation is not cheap and time-consuming, quality management systems are important so that organizations can achieve long-term success through ERP user satisfaction by relying on strategies, data, and effective communication. to integrate the quality discipline into corporate activities and culture. Given the importance of this focus, it is hoped that research whose focus data can be used can be widely used as research.

\section{REFERENCES}

1. D. J. Teece, "A capability theory of the firm: an economics and (Strategic) management perspective," New Zeal. Econ. Pap., vol. 53, no. 1, pp. 1-43, 2019, doi: 10.1080/00779954.2017.1371208.

2. S. M. Chege, D. Wang, and S. L. Suntu, "Impact of information technology innovation on firm performance in Kenya," Inf. Technol. Dev., vol. 26, no. 2, pp. 316-345, 2020, doi: 10.1080/02681102.2019.1573717.

3. H. Hertz, "The Impact of Baldrige on Organizational Performance," $J$ Qual. Particip., vol. 35, no. 1, pp. 191-197, 2012.

4. R. Martin-Rojas, V. J. Garcia-Morales, and N. Gonzalez-Alvarez, "Technological antecedents of entrepreneurship and its consequences for organizational performance," Technol. Forecast. Soc. Change, vol. 147, no. May 2017, pp. 22-35, 2019, doi 10.1016/j.techfore.2019.06.018.

5. U. Jayawickrama, S. Liu, and M. Hudson Smith, "Empirical evidence of an integrative knowledge competence framework for ERP systems implementation in UK industries," Comput. Ind., vol. 82, pp. 205-223, 2016, doi: https://doi.org/10.1016/j.compind.2016.07.005.

$$
\begin{aligned}
& \text { Blue Eyes Intelligence Engineering } \\
& \text { and Sciences Publication }
\end{aligned}
$$$$
\text { Published By: }
$$

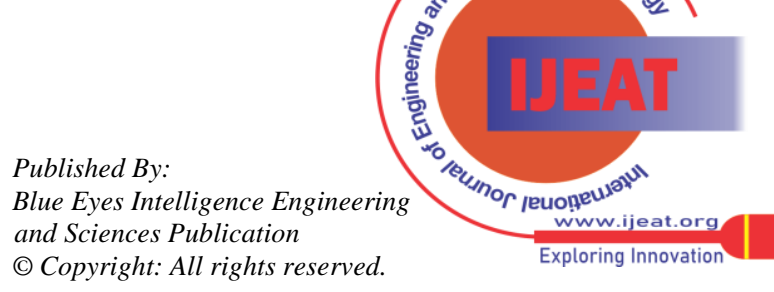


6. G. Mehralian, J. A. Nazari, and P. Ghasemzadeh, "The effects of knowledge creation process on organizational performance using the BSC approach: the mediating role of intellectual capital," J. Knowl. Manag., vol. 22, no. 4, pp. 802-823, 2018, doi: 10.1108/JKM-10-2016-0457.

7. A. Collie et al., "Recovery Within Injury Compensation Schemes: A System Mapping Study," J. Occup. Rehabil., vol. 29, no. 1, pp. 52-63, 2019, doi: 10.1007/s10926-018-9764-Z.

8. S. Katuu, "Enterprise Resource Planning: Past, Present, and Future," New Rev. Inf. Netw., vol. 25, no. 1, pp. 37-46, 2020, doi: 10.1080/13614576.2020.1742770.

9. A. Trigo, F. Belfo, and R. P. Estébanez, "Accounting Information Systems: Evolving towards a Business Process Oriented Accounting," Procedia Comput. Sci., vol. 100, pp. 987-994, 2016, doi: https://doi.org/10.1016/j.procs.2016.09.264.

10. P. J. Rondeau and L. A. Litteral, "Evolution of manufacturing planning and control systems: From reorder point to enterprise resource planning," Prod. Invent. Manag. J., vol. 42, no. 2, pp. 1-7, 2001.

11. A. Susanto and Meiryani, "How business use information systems?," Int. J. Sci. Technol. Res., vol. 8, no. 1, pp. 145-147, 2019.

12. Syahrul, N. Alim, Pairin, and J. Nur, "Utilization of managemen information systems in managerial supervision at IAIN Kendari," Int. J. Recent Technol. Eng., vol. 8, no. 1C2, pp. 392-395, 2019.

13. R. P. Vega, A. J. Anderson, and S. A. Kaplan, "A Within-Person Examination of the Effects of Telework," J. Bus. Psychol., vol. 30, no. 2, pp. 313-323, 2015, doi: 10.1007/s10869-014-9359-4

14. T. A. Reyath and B. Y. Kamarul, "The Effect of Management Information System on Organizational Performance: A Survey Study at Missan Oil Company in Iraq,” J. Glob. Sci. Res., vol. 2, no. July, p. 135, 2019.

15. Z. Alkhazali, A. Abu-Rumman, N. Khdour, and K. Al-Daoud, "Empowerment, hrm practices and organizational performance: A case study of jordanian commercial banks," Entrep. Sustain. Issues, vol. 7 no. 4, pp. 2991-3000, 2020, doi: 10.9770/jesi.2020.7.4(28).

16. H. C. Chae, C. E. Koh, and V. R. Prybutok, "Information technology capability and firm performance: Contradictory findings and their possible causes," MIS Q. Manag. Inf. Syst., vol. 38, no. 1, pp. 305-326, 2014, doi: 10.25300/MISQ/2014/38.1.14.

17. P. Chatzoglou, D. Chatzoudes, and G. Apostolopoulou, "Antecedents and outcomes of ERP implementation success," in 2016 Federated Conference on Computer Science and Information Systems (FedCSIS), 2016, pp. 1253-1262.

18. J.-S. Chou and J.-H. Hong, "Assessing the impact of quality determinants and user characteristics on successful enterprise resource planning project implementation," J. Manuf. Syst., vol. 32, no. 4, pp. 792-800, 2013, doi: https://doi.org/10.1016/j.jmsy.2013.04.014.

19. D. Garcia-Smith and J. A. Effken, "Development and initial evaluation of the Clinical Information Systems Success Model (CISSM)," Int. J. Med. Inform., vol. 82, no. 6, pp. 539-552, 2013, doi: 10.1016/j.ijmedinf.2013.01.011.

20. C. K. Hou, "The effects of IT infrastructure integration and flexibility on supply chain capabilities and organizational performance: An empirical study of the electronics industry in Taiwan," Inf. Dev., vol. 36, no. 4, pp. 576-602, 2020, doi: 10.1177/0266666919884352.

21. S.-K. Lee and J.-H. Yu, "Success model of project management information system in construction," Autom. Constr., vol. 25, pp. 82-93, 2012, doi: https://doi.org/10.1016/j.autcon.2012.04.015.

22. S. Petter and E. R. McLean, "A meta-analytic assessment of the DeLone and McLean IS success model: An examination of IS success at the individual level," Inf. Manag., vol. 46, no. 3, pp. 159-166, 2009, doi: 10.1016/j.im.2008.12.006

23. N. Banaeianjahromi and K. Smolander, "What do we know about the role of enterprise architecture in enterprise integration? A systematic mapping study," J. Enterp. Inf. Manag., vol. 20, no. 1, pp. 160-164, 2016, doi: https://doi.org/10.1108/JEIM-12-2014-0114.

24. E. Maulina, A. Miftahuddin, D. Gaol, D. Syafarudin, and M. Mutofid, "A Systematic mapping study on competitive advantage for Micro, Small and Medium Enterprises," no. January, 2019, doi: 10.4108/eai.8-12-2018.2284044.

25. M. Kuhrmann, P. Diebold, and J. Münch, "Software process improvement: A systematic mapping study on the state of the art," PeerJ Comput. Sci., vol. 2016, no. 5, 2016, doi: 10.7717/peerj-cs.62.

26. Y. Tribis, A. El Bouchti, and H. Bouayad, "Supply chain management based on blockchain: A systematic mapping study," MATEC Web Conf., vol. 200, 2018, doi: 10.1051/matecconf/201820000020.

27. K. Petersen, R. Feldt, S. Mujtaba, and M. Mattsson, "Systematic mapping studies in software engineering," 12th Int. Conf. Eval. Assess. Softw. Eng. EASE 2008, no. June, 2008, doi:

Published By:

Blue Eyes Intelligence Engineering

and Sciences Publication

Erna Maulina, Lecturer at Padjadjaran University, Faculty of Social and Political Sciences, majoring in administration with expertise in business strategy and small and medium enterprise thinking. There are already 60 publications. There are 6 books registered in the national library. The samples used in the studies carried out were in the territory of Indonesia.

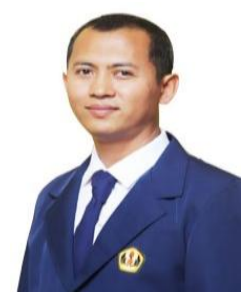

Margo Purnomo, Lecturer in the Department of Business Administration, Faculty of Social and Political Sciences, Padjadjaran University. In 2017-2020 he served as Coordinator of the Postgraduate Business Administration Program. Furthermore, in 2020-2024 as Head of the Applied Logistics Business Undergraduate Study Program. The expertise developed is entrepreneurship, entrepreneurial management, contextual entrepreneurship, and knowledge-based strategic entrepreneurship. There are 42 scientific papers that have been published and are actively fostering entrepreneurship literacy at the House of Entrepreneurship and Self-Development Foundation. 